\title{
Mercados como espelho
}

Juan Pablo Pardo-Guerra

Mark Granovetter é provavelmente um dos autores mais exitosos da sociologia contemporânea, tendo acumulado mais de 100 mil citaçóes ao longo da sua carreira. O sucesso de Granovetter é parcialmente explicável pelas várias inovações metodológicas que introduziu na disciplina. Devemos a Granovetter uma parte considerável das metodologias quantitativas por meio das quais se tornou possível analisar a dinâmica e o papel das redes sociais na criação de fenômenos coletivos (Granovetter, 1973; 1978). Além de suas contribuições à sociologia quantitativa e ao estabelecimento da teoria de redes nas ciências sociais, Granovetter é conhecido na sociologia econômica por um aporte metafórico que se tornou parte essencial de nosso repertório conceitual: desde a publicação do artigo "Economic action and social structure" (Granovetter, 1985), falar de mercados inseridos (ou embedded) em relações sociais virou um lugar-comum na literatura sociológica e na nossa forma de entender as conexões entre os mundos econômico e social.

Apesar de ser uma metáfora importante e aparentemente revolucionária, o conceito de embeddedness mostra uma certa continuidade com respeito a uma ampla tradição intelectual nas ciências sociais, que opõe "mercados" e transaçốes impessoais a "sociedade" e densidade simbólica das relações interpessoais (um fato observado, por exemplo, por Krippner e Alvarez, 2007). Assim, pensar em relaçóes econômicas como entidades inseridas em relações sociais é afirmar, de forma qualificada e até certo ponto nuançada, uma distinção teórica (e quem sabe até ontológica) entre mercados e sociedade. Neste breve artigo, questiono tal distinção. O que acontece, 
pergunto, quando os mercados são pensados não como uma coleção de transações efêmeras e distantes do processo social, mas como reflexos da sociedade? O que acontece quando consideramos os mercados como espelhos do mundo, mais do que como mecanismos abstratos e impessoais de produção, troca e exploração?

Meu argumento lançará mão de dois movimentos conceituais complementares que visam a repensar os mercados como processos eminentemente sociais. Em primeiro lugar, discuto brevemente como e por que a relação de mercado pode ser entendida como uma relação social - tal como, até certo ponto, se passa em comunidades ditas tradicionais, nas quais os mercados e os sistemas de parentesco não diferem radicalmente uns dos outros. Tendo repensado a relação de mercado, apresentarei, em segundo lugar, os mercados como realizações burocrático-administrativas. Em vez de contrastar mercados (sistemas horizontais) e hierarquias (estruturas verticais), proponho pensá-los como superfícies que se desenvolvem sobre um mundo organizacional complexo e intrincado que eles ocultam. Como exemplos das vantagens conceituais desse movimento, tomarei os casos empíricos da história das bolsas de valores dos Estados Unidos e de São Paulo, que ilustram a maneira pela qual os mercados podem ser entendidos como espelhos das suas realidades sociais mais do que como sistemas abstratos e desvinculados do mundo impessoal.

\section{Mercados como comunidade}

Para repensar a ontologia do mercado, considero importante voltar ao momento histórico em que o conceito do econômico foi subtraído do mundo social - o que o filósofo Charles Taylor (2002) chama da great disembedding. Embora a utopia liberal do mercado já estivesse estabelecida no começo do século XIX, como mostra Polanyi (1944), a separação analítica entre os mundos econômico e social só foi consolidada no começo do século XX, em parte como uma consequência do Methodenstreit ${ }^{1}$ (Calhoun, 1998), em parte como um produto da maturação disciplinar das ciências sociais e das técnicas econômicas como técnicas administrativas (Mirowski, 1991). A transição é particularmente clara no trabalho de Max Weber, um intelectual marcado pela tensão entre, por um lado, as já estabelecidas escolas comparativa e histórica e, por outro, a relativamente nova modalidade de pensamento, caracterizada pela abstração e pela procura de categorias universais para entender o processo modernizador.

1. Methodenstreit der Nationalökonomie ("disputa de métodos na macroeconomia") é o nome pelo qual ficou conhecido o debate nos meios acadêmicos na área da macroeconomia de língua alemã, transcorrido nas décadas de 1880 e 1890, opondo as chamadas Escola Austríaca e Escola Historicista Alemã [N. E.]. 
Grande parte do trabalho de Weber sobre mercados é, desafortunadamente, fragmentário e indireto. O mercado, como reconheceu Collins (1986), é um tema recorrente na obra de Weber, conquanto só receba tratamento direto em um artigo breve e incompleto, publicado postumamente. Nessa reflexão, Weber assume a imagem contemporânea dos mercados, que, para ele, são "arquétipos de toda ação social racional, uma coexistência e sequência de relações associativas racionais, cada uma das quais é especificamente efêmera, na medida em que deixa de existir com o ato de trocar mercadorias" (Weber, 1978, p. 635). A importância da definição de Weber alcança seu pleno significado no alemão original: os mercados são Vergesellschaftung (Idem, p. 635). É particularmente notável que Vergesellschaftung tem pelo menos dois significados. Em um primeiro lugar, a palavra descreve a ideia de associação, ou seja, representa o mercado como uma associação efêmera e racional entre compradores e vendedores, os quais se encontram com o objetivo de troca. Entretanto, Vergesellschaftung tem um segundo significado: é a produção da sociedade, o ato de construir associações e sociabilidades sob formas específicas. O mercado é, nesse segundo sentido, um projeto que visa a construir relações tornando-se, por meio delas, uma comunidade especifica. Trata-se, por isso mesmo, de uma instituição plenamente social.

A referência ao conceito de comunidade é clara no trabalho de Weber, que apresenta explicitamente a ideia do Marktgemeinschaft (comunidade de mercado) como um importante eixo conceitual. Tal noção reverbera aproximações contemporâneas aos mercados, nas quais a ênfase é colocada nas comunidades de compradores e vendedores mais do que nos processos impessoais de concorrência e troca: o leitor pode considerar aqui análises antropológicas clássicas (Geertz, 1979), assim como pesquisas mais recentes (Hertz, 1998) que utilizam a ideia de comunidade como um dispositivo conceitual para articular discussões sobre as estruturas sociais e econômicas dos mercados. Trata-se de um aspecto importante nesses trabalhos, que aproximam processos de mercado e processos de interação interpessoal, permitindo imaginar as relações de mercado como vínculos densos, comunitários e até íntimos. Seguindo um caminho paralelo, a sociologia relacional de Viviana Zelizer enfatiza, também, a natureza social das relações econômicas: uma troca não é só uma oportunidade para intercambiar bens, mas também um momento para reafirmar, contestar e reinventar categorias sociais (Zelizer, 2012). Embora o trabalho de Zelizer mostre claramente a importância de se entender o processo de intercâmbio (e sobretudo o uso de moedas) como um processo social, ele mantém de maneira implícita uma certa distinção ontológica entre relações interpessoais e relações econômicas e de mercado. Apesar de existirem como parte do mesmo pacote relacional, constituem dimensões diferentes. Porém, o que acontece se, em vez de mantermos uma ontologia 
divergente, pensarmos em relações econômicas e relações sociais como elementos de uma mesma dimensão?

\section{Mercados como organização}

Um possível ponto de partida para reinterpretar a natureza das relações de mercado é o trabalho crítico de Marilyn Strathern, que examina a ideia de relação na teoria antropológica moderna. A preocupação principal de Strathern é com a qualidade e a natureza do parentesco (ou kinship), um tema que ocupa lugar central na história da teoria antropológica. Usando discussões sobre kinship como uma lente analítica, Strathern discerne a construção de categorias modernas - cultura, natureza, propriedade, indivíduo - como parte de um processo de interconexão entre as estruturas da propriedade privada, o conhecimento científico e os dispositivos criados pela lei e pelo sistema jurídico.

No contexto da discussão sobre mercados, o trabalho de Strathern é particularmente interessante por sua capacidade de conectar o mundo das relações densas, simbolicamente carregadas e interpessoais (como parentesco ou kinship) com estruturas abstratas, categóricas e conceituais (como organizações, tecnologias ou práticas racionais do fazer burocrático). Para Strathern, a relação antropológica é composta por um elemento "conceitual", ou categórico, e um elemento interpessoal; o geral e o particular, para dizê-lo de uma outra forma. Afirma a autora:

\footnotetext{
Por um lado, há relações que são vistas como criadoras de conexões por meio da lógica de um poder de articulação que adquire seu próprio momentum conceitual; por outro, há relações que são conduzidas em termos interpessoais, conexões entre pessoas talhadas por uma história precisa e particular (Strathern, 2005, p. 7).
}

Entender a relação antropológica, sugere Strathern, requer necessariamente considerar "o conjunto" conceitual e pessoal, articular as lógicas de conexão categórica com a forma pela qual as pessoas criam relações em termos interpessoais, ou, em suas palavras:

É por meio da interação com pessoas que interações diversas e novas conexões tornam-se concebíveis intelectualmente [o interpessoal cria possibilidades para o conceitual], ainda que seja por meio da criação de conceitos e categorias que as conexões desenvolvem uma vida social própria [o conceitual como um terreno para o potencial interpessoal] (Strathern, 2005, p. 8). 
Para Strathern, a importância de uma análise conjunta é exemplificada no estudo de sistemas de parentesco. Neles, o aparato conceitual do direito (que é eminentemente abstrato) reúne a experiência aparentemente densa e cotidiana do familiar, criando definições acerca do que é esperado em termos das conexões interpessoais. A lei não é independente dessas conexões, pois, mediante processos judiciais e batalhas sobre quem está ligado a quem, novas categorias são produzidas. Da mesma forma, a lei molda a nossa experiência cotidiana de formas distintas: define quem pode casar com quem, quem é considerado um irmão, quem tem responsabilidades parentais. Todas essas são questões de técnica jurídica que afetam nossa capacidade de criar grupos e as conexões que estabelecemos em nossas vidas pessoais.

Existem, assim, consequências claras quando analisamos o conjunto dessas relações no contexto do mercado. Se reconhecemos, como ponto de partida, que a relação de mercado é uma relação comunitária (seguindo Weber), é possível perguntar quais são as conexões entre conceitos e categorias que tornam possível a criação de relações (por efêmeras que sejam) no intercâmbio econômico. Considerarmos unicamente as relações entre os agentes sociais nos levaria a ignorar o trabalho de produção de categorias (geralmente invisível, burocrático, administrativo) que sustenta a própria possibilidade das relações de mercado. Isso porque, para cada relação de mercado, para cada instância de troca, existe uma considerável infraestrutura que torna o intercâmbio possível, inteligível e legítimo.

No mercado financeiro, por exemplo, a relação de compra e venda não é realmente fugaz: quando dois agentes entram em acordo sobre a compra ou a venda de um instrumento financeiro, não ficam imediatamente quites. Por mais rápidos que sejam o mercado e a transação, compradores e vendedores só rompem a relação uma vez que concluem um longo e demorado processo de compensação e liquidação (settlement). Além de ser eminentemente burocrático (um processo tipicamente racional, no sentido weberiano, que precisa do cálculo minucioso de cada transação), a compensação e a liquidação são processos coletivos. À diferença de uma compra e venda em uma feira, onde o produto e o dinheiro trocam de mãos quase que imediatamente, o processo de liquidação no mercado financeiro é caracterizado pelo chamado netting, mecanismo pelo qual os membros de um mercado pagam a dívida agregada em vez da dívida associada a transações individuais. No netting, todas as transações são coletadas ao longo de um período específico (um dia, por exemplo, ou uma semana laboral), criando assim um sistema coletivo de dívida sobre o qual todos os agentes têm responsabilidade. Efetivamente, enquanto não se fecha o netting e as posições do mercado não são liquidadas, os agentes permanecem ligados. Tanto é assim que um dos riscos centrais do mercado é a possibilidade da falência do mecanismo de compensação e liquidação - conhecida como settlement 
risk, o chamado "risco sistêmico" que atinge todos os participantes do mercado (Riles, 2011).

Pensar no mercado simplesmente como uma sequência de interações efêmeras seria, portanto, incorreto. O mercado é, antes que nada, um mecanismo que permite e regulamenta a formação de relações através de conhecimentos específicos, de práticas burocráticas e de dispositivos administrativos. Tal conexão é precisamente a dialética que se perde quando nos atemos ao marco conceitual da sociologia convencional. Isso porque, ao atentarmos apenas para as relações interpessoais, perde-se de vista o papel das infraestruturas do mercado.

Entendo por infraestrutura um sistema tecnológico (incluindo categorias, padrões, rotinas organizacionais e dispositivos físicos) usado de forma prática e operacional por agentes sociais e que é invisível para eles. A infraestrutura é sempre uma condição, não uma ontologia: o que é infraestrutural para mim pode não ser para outra pessoa (no meu cotidiano, penso pouco sobre os padrões de interconectividade usados por meu computador, embora eles sejam debatidos e transformados por uma rede enorme de tecnólogos, administradores e usuários). A perspectiva infraestrutural é diferente das abordagens institucionais, culturais e performativas da sociologia econômica atual. Em contraste com perspectivas institucionais, por exemplo, pensar em infraestruturas implica considerar sistemas tecnológicos, que não pertencem a um campo organizacional em particular. Assim, uma infraestrutura não é definida por uma concepção de controle coerente nem por estruturas de governança compartilhadas por usuários. Uma infraestrutura não responde a uma lógica institucional única nem é produto de um só dispositivo tecnológico. Pelo contrário, as infraestruturas surgem como objetos de fronteira, coordenando, mas simultaneamente diferenciando, as comunidades epistêmicas, culturais e institucionais que dependem de sua operação.

Por fim, entendo que a peculiar mistura de um Weber heterodoxo e uma Strathern ortodoxa nos brindaria com uma nova perspectiva do mercado. Por um lado, a ideia do mercado como instituição social não é insólita no contexto da obra teórico-histórica de Weber. Para Weber, por exemplo, os mercados estão definidos por uma ética especifica, que facilita a troca entre compradores e vendedores. A ética de mercado é também um produto institucional: convenções comportamentais animam a política de status e a legitimidade nos mercados, como Weber deixa claro em sua análise da bolsa de valores (Weber, 2000). Mas uma ética é uma invocação de responsabilidade e, como forma de conhecimento e de avaliação coletiva, implica reconhecer as responsabilidades de um agente para com os outros; é criar relações, "imaginar [...] um parente de um parente, relações entre relações" (Strathern, 1992, p. 8). As burocracias do mercado - sejam elas processos técnicos de liquidação ou 
regras de uso e interconexão das plataformas eletrônicas de compra e venda - cristalizam e reproduzem tais relações. Nesse sentido, a dualidade stratherniana torna-se aparente: as infraestruturas geram relações de mercado, e por meio da concorrência, entendida como um processo abrangente e cultural, as relações de mercado mudam as infraestruturas.

As várias culturas da velocidade

A metáfora que surge da conjunção teórica apresentada na seção anterior é relativamente oposta à metáfora tradicional do mercado. $\mathrm{O}$ conceito moderno de mercado, sugeriu Barber (1977), é eminentemente abstrato e frequentemente localizado, em oposição à sociabilidade densa e não racional das interaçóes pessoais. A separação entre as categorias do social e do econômico - ou a existência de "mundos hostis", como cunhado por Zelizer (2005) - é, contudo, analiticamente desnecessária. Se todo mercado é uma comunidade - e requer uma infraestrutura material, categorial e prática -, a representação do que seja o mercado, ao contrário do que normalmente pensamos, poderia aproximar-se de entidades mais mundanas e cotidianas, como a casa, a família, a organização, a comunidade política. O mercado deixa de ser uma forma particular do social e é mais bem pensado se concebido como um espelho de relações, categorias, conhecimentos e práticas, que extravasam qualquer categoria econômica.

Para bem entender o alcance da representação de mercados como espelhos, é possível estudar a história de um tipo de mercado particularmente paradigmático do capitalismo moderno. Os mercados de valores constituem-se, em tal situação exemplar, em pelo menos dois níveis conceituais. Primeiro, os mercados de valores ficam no centro do imaginário econômico contemporâneo. Tanto Walras quanto Marshall e Pareto consideraram as bolsas de valores como os mercados mais próximos ao mercado idealizado e perfeito da teoria econômica. O imaginário sociológico clássico replica tal distinção: Simmel, por exemplo, considera o mercado de valores como um motor da segmentação que dá origem ao sistema capitalista atual (Simmel, 2004). Evidenciar como se revela o conjunto stratherniano nos mercados financeiros é, assim, um exercício de reconhecer a constituição mútua de relações e infraestruturas em um caso extremo, tanto para a teoria econômica como para as teorias sociológica e antropológica. Em um segundo nível, representar os mercados como espelhos responde a uma tendência relativamente clara na abordagem dos mercados financeiros pelas ciências sociais contemporâneas: apesar de terem amadurecido consideravelmente ao longo da última década, a sociologia e a antropologia das finanças assumem os mercados financeiros no singular: o tema é, quase sempre, "o mercado 
financeiro", em geral. E embora ele opere localmente, é com frequência pensado como um fenômeno global. Por detrás de uma linguagem acerca de interconexões internacionais, globalização e elites transacionais (ver, por exemplo, Sassen, 2001), as pesquisas partem do suposto de que as finanças em Paris, Nova York, Singapura e São Paulo são farinha do mesmo saco.

Existem vários motivos para pensar que os mercados financeiros contemporâneos são, para todo fim prático, estruturalmente equivalentes. Com efeito, embora apresentassem variações organizacionais nos séculos XIX e XX, os mercados financeiros modernos são altamente isomórficos. As tecnologias são similares (quase todos operam com um carnê eletrônico de compra e venda); as regulamentações são comparáveis graças não só às conexões institucionais entre organismos de governança, mas também ao poder hegemônico dos mercados e das cortes norte-americanas e europeias; e, por fim, apesar de algumas pequenas diferenças, os contratos negociados nos diferentes mercados no mundo são, também, praticamente intercambiáveis.

A aparente igualdade, entretanto, não passa de uma ilusão. Cada mercado representa e reproduz, de forma nítida, o contexto social do qual faz parte. Consideremos dois casos: os mercados financeiros norte-americanos e o mercado financeiro brasileiro.

Comecemos pelos mercados norte-americanos. Naquele país, a literatura recente apresenta uma visão do setor dominada primordialmente pela crescente racionalização e automatização da compra e venda de instrumentos (Geisst, 2012; Arnuk e Saluzzi, 2012, Castelle et al., 2016). Enquanto alguns autores identificam processos culturais no desenvolvimento histórico dos mercados de valores norte-americanos (MacKenzie, 2011), a grande narrativa é sobre como, com cunho ideológico, o mercado norte-americano substituiu pessoas por algoritmos no processo de troca. Tal visão é bastante razoável: pressões da concorrência nos Estados Unidos levaram, efetivamente, a uma corrida armamentista entre os grandes corretores de bolsa. Assim, hoje em dia, a velocidade nas transações na bolsa de Nova York se mede cada vez mais em microssegundos (ou seja, milionésimos de segundo). Em uma perspectiva clássica, é como se o mercado financeiro virasse uma utopia abstrata, um conjunto de associações efêmeras e calculadas, como produto de uma inescapável intervenção neoliberal no desenho dos sistemas, das regras e das interações do setor (Krippner, 2011; Mirowski, 2013; Ho, 2009).

O incremento da velocidade dos mercados norte-americanos pode ser compreendido sob outra perspectiva: em particular, é possível ver cada transação efêmera como uma síntese e reprodução de uma longa história tecnológica e política dirigida a construir um tipo de comunidade especifica. Até certo ponto, o desenvolvimento de sistemas automatizados no mercado norte-americano resulta de uma série de 
intervenções regulatórias ocorridas na década de 1960. Elas estiveram voltadas para criar um sistema nacional, único e integrado a partir das múltiplas bolsas regionais que caracterizavam o setor financeiro à época, quando a bolsa de Nova York, sempre hegemônica, concorria com outras bolsas pelo controle do mercado, de São Francisco a Boston. A partir de 1963, a Securities and Exchange Commission (sEC), órgão responsável pela regulação do setor financeiro não bancário norte-americano, viu no uso de telecomunicações uma oportunidade para unificar mercados por meio da tecnologia.

Com o projeto da unificação, tanto a SEC como os pequenos participantes do mercado pretendiam gerar não só um sistema de compra e venda mais eficiente em termos econômicos, mas sobretudo um sistema de corresponsabilidade moral: segundo alguns dos primeiros defensores de projetos de unificação, vincular as várias bolsas norte-americanas - ou até mesmo substituí-las por um mercado eletrônico centralizado controlado pela SEC - levaria a uma participação mais justa, sobretudo para os pequenos corretores e investidores que começavam a surgir no cenário norte-americano do pós-guerra. O projeto de criar um mercado único era, assim, um projeto ético-moral. Isso é visível não só no discurso moralizador da SEC e de alguns de seus detratores (Pardo-Guerra e MacKenzie, 2014), mas também no discurso associado a alguns dos desenvolvedores dos primeiros sistemas automatizados de compra e venda (Pardo-Guerra, 2015), que tinham um objetivo claramente ético, qual seja, gerar as condições de um mercado igualitário, anônimo e transparente.

A criação de um mercado único carecia, porém, de uma base, de uma infraestrutura que servisse como eixo articulador, facultando aos atores diferenciar o que constitui uma relação legítima de uma falsa, e definir o padrão do sistema. Surgiu, assim, o conceito de price-time priority, que foi, talvez, o eixo articulador mais importante do sistema financeiro norte-americano. Segundo a lógica do price-time priority, as instruções para comprar e vender ações no mercado deveriam ser consideradas sequencialmente: primeiro, pelo preço oferecido e, segundo, pelo momento no qual a ordem foi recebida em nivel nacional. O mercado financeiro norte-americano foi construído, assim, como uma comunidade definida pela cotemporalidade das transações. À diferença do pregão, em que o tempo é bilateral, negociável e assimétrico, o tempo nos mercados financeiros eletrônicos é global, compartilhado e estruturado por uma vasta rede de infraestruturas públicas e privadas. A ética do mercado é, assim, uma ética temporal: na medida em que as instruções de compra e venda são ordenadas pelo princípio de preço e tempo, o status moral de cada transação é determinado não pela intencionalidade dos agentes que as geram, mas por sua lógica no contexto operacional da infraestrutura do sistema. A compra e a venda de 
instrumentos em altas velocidades não é, pois, um problema de especulação, uma vez que o comportamento de cada transação é consistente com as regras técnicas e operativas do carnê eletrônico de compra e venda.

O mercado cotemporal dos Estados Unidos é claramente um produto ideológico. O princípio de prioridade em preço e tempo é particularmente compatível com uma longa tradição de liberalismo político que julga o valor dos indivíduos em termos de mérito pessoal (rapidez, por exemplo). Todavia, a intenção de estender o sistema a todos os cantos dos Estados Unidos deixa clara uma outra inspiração ideológica: a de uma democracia financeira, segundo a qual todo cidadão é responsável pela sua segurança econômica, o que demanda um sistema que permite a participação via um mercado único e nacional. Em cada transação, o mercado norte-americano procura reproduzir uma nova utopia particular - libertária, democrática, econômica - pela criação de uma comunidade de mercado nacional.

Mas nem todos os mercados têm o mesmo objetivo, a mesma história ou a mesma dinâmica relacional. A esse respeito, o Brasil é um caso particularmente interessante, pois a principal bolsa do país é também uma das bolsas mais tecnologicamente avançadas do mundo. Analistas de mercados frequentemente apresentam os sistemas da BM\&FBovespa como comparáveis aos de Londres e Nova York. Efetivamente, a Bovespa foi inovadora no âmbito financeiro global: enquanto Londres e Nova York ainda eram basicamente sistemas analógicos, baseados em transações de compra e venda no pregão, São Paulo já tinha começado a desenvolver sistemas eletrônicos em 1982, tornando-se uma instituição pioneira no processo de digitalização - em 1997, o sistema original (CATs, baseado no sistema introduzido anteriormente nas bolsas de Toronto e Paris) foi modernizado com a introdução da Mega Bolsa; em 1999, o sistema home broker levou aos lares dos investidores a possibilidade de comprar e vender instrumentos financeiros na Bovespa usando a internet (Müller, 2006; 2007).

A olhos mais apressados, poderia parecer que tais avanços teriam replicado o projeto de democratização financeira que caracterizou o desenvolvimento tecnológico do mercado financeiro norte-americano. A comparabilidade das tecnologias financeiras do Brasil e dos Estados Unidos esconde, porém, uma divergência cultural e relacional importante: os projetos de comunidade financeira em ambos países são indiscutivelmente diferentes. Consideremos, por exemplo, quem é parte da comunidade do mercado em cada caso. Enquanto o ideal da democracia financeira norte-americana é inclusivo (em 2011, 54\% da população norte-americana tinha algum investimento no mercado financeiro, seja em ações, seja em fundos de investimento compostos por ações), no Brasil, é exclusivo (em 2015, o número de investidores não supera os 600 mil, ou seja, menos de $0,3 \%$ da população do país). Apesar de mais de três décadas de inovação, os sofisticados sistemas da Bovespa não podem ser considerados parte 
de um processo expansivo e inclusivo, de um projeto de mercado voltado para criar uma comunidade nacional. Os bancos e as corretoras de valores que participam do setor financeiro limitam, por meios tecnológicos, institucionais ou administrativos, a participação de setores populares: as taxas de intermediação no Brasil estão entre as maiores da região, controladas por um pequeno conjunto de grandes corretores e bancos com presença no setor financeiro; o mercado é relativamente lento (o valor do mercado brasileiro superou os 1,2 trilhões de dólares em 2015, mas movimenta em torno de 3,7 bilhões de dólares por dia, menos do que a movimentação diária da Apple no mercado norte-americano); e as tecnologias teoricamente democráticas só reproduzem padrões existentes (o home broker da Bovespa é, por exemplo, um produto eminentemente elitizado, pois nem todos os lares têm acesso ao mercado, só aqueles que já formam parte de uma comunidade restrita e definida pela posse de meios e poder econômico). A Bovespa é, assim, um espelho da desigualdade de acesso, da concentração da riqueza e da riqueza mesma do Brasil.

\section{Conclusão}

O discurso moderno propõe que os mercados, como um mecanismo único e exemplar, seriam uma solução para os problemas sociais, . Os mercados, sugere Hernando de Soto (2000), são uma forma de combater a pobreza por via do desenvolvimento econômico. Os mercados eficientes, escreveu Gary Becker (1957), geram incentivos que evitam a discriminação no mercado de trabalho. Os mercados, sugeriu Friedrich von Hayek (1948), coletam e distribuem a informação melhor que qualquer burocracia. Para outros pensadores, o mercado é gerador dos problemas-chave da sociedade atual (ver, por exemplo, Mirowski, 1988). Por outro lado, a crítica acadêmica dos mercados sublinha a importância das instituições (Polanyi, 1944). Os mercados são, como discutem Neil Fligstein (2002) e Frank Dobbin (1994), resultados de culturas institucionais específicas que facilitam o intercâmbio de produtos e serviços, tão infalíveis quanto o contexto organizacional do qual fazem parte.

Neste breve ensaio, proponho que devemos transcender esse excepcionalismo econômico, repensando mercados como conjuntos de relações que reproduzem formas sociais preexistentes, desde desejos e utopias políticas, até padrões de concentração e desigualdade. A questão que levou Granovetter a propor o conceito de embeddedness - suscitada a partir de uma breve referência à controvérsia entre teorias substantivistas e formalistas sobre a economia - tem, talvez, uma solução alternativa. A crítica não é necessariamente contra ou a favor do mercado, mas sobre a natureza dos sujeitos criados na relação econômica. A possibilidade de atuação política em relação ao papel dos mercados no mundo contemporâneo está dada, assim, por uma 
reformatação da relação econômica, em vez de sua reificação ou completa rejeição. A solução não é conter o mercado, o que supõe uma separação clara e nítida entre econômico e social. A solução é, talvez, o que Donna Haraway (2015) indica como alternativa ao capitalismo e ao antropoceno que dele deriva: make kin, not family; construindo as relações, as responsabilidades e as identidades coletivas ocultas em um processo que é, para muitos, putativamente individualista e associal.

\section{Referências Bibliográficas}

ARNuK, Sal \& SALUZZI, Joseph. (2012), Broken markets: how high frequency trading and predatory practices on Wall Street are destroying investor confidence and your portfolio. Upper Saddle River, FT Press.

BARBER, Bernard. (1977), "Absolutization of the market: some notes on how we got from there to here". In: Dwokin, Geral et al (orgs.). Markets and morals. Washington, DC, Hemisphere, pp. 15-31.

BeCKer, Gary S. (1957), The economics of discrimination. Chicago, University of Chicago Press.

Calmoun, Craig. (1998), "Explanation in historical sociology: narrative, general theory, and historically specific theory”. American Journal of Sociology, 3 (104): 846-871.

Castelle, Michael et al. (2016), "Where do electronic markets come from? Regulation and the transformation of financial exchanges". Economy and Society, 2 (45): 166-200.

Collins, Randall. (1986), Weberian sociological theory. Cambridge, Cambridge University Press.

De Sото, Hernando. (2000), The mystery of capital: why capitalism triumphs in the West and fails everywhere else. Nova York, Basic Books.

Dobbin, Frank. (1994), Forging industrial policy: the United States, Britain, and France in the railway age. Cambridge, Cambridge University Press.

FLIGSTEIN, Neil. (2002), The architecture of markets: an economic sociology of twenty-first-century capitalist societies. Princeton, Princeton University Press.

Geertz, Clifford. (1979), "Suq: the bazaar economy in Sefrou”. In: Geertz, Clifford et al. Meaning and order in Moroccan society: three essays in cultural analysis. Cambridge, Cambridge University Press, pp. 123-313.

GeIsst, Charles R. (2012), Wall Street: a history from its beginnings to the fall of Enron. Nova York, Oxford University Press.

Granovetter, Mark S. (1973), “The strength of weak ties”. American Journal of Sociology, 6 (78): 1360-1380.

. (1978), "Threshold models of collective behavior". American Journal of Sociology, 6 (83): 1420-1443.

. (1985), "Economic action and social structure: the problem of embeddedness". American Journal of Sociology, 3 (91): 481-510. 
Haraway, Donna. (2015), "Anthropocene, capitalocene, plantationocene, chthulucene: making kin”. Environmental Humanities, 1 (6): 159-165.

HaYeK, Friedrich. (1948), Individualism and economic order. Chicago, University of Chicago Press.

HerTz, Ellen. (1998), The trading crowd: an ethnography of the Shanghai stock market. Cambridge, Cambridge University Press.

Ho, Karen. (2009), Liquidated: an ethnography of Wall Street. Durham, Duke University Press.

KRIPPNeR, Greta R. (2011), Capitalizing on crisis: the political origins of the rise of finance. Cambridge, Harvard University Press.

Krippner, Greta R. \& Alvarez, Anthony S. (2007), "Embeddedness and the intellectual projects of economic sociology”. Annual Review of Sociology, 33: 219-240.

MacKenzie, Donald. (2011), "The credit crisis as a problem in the sociology of knowledge". American Journal of Sociology, 6 (116): 1778-1841.

Mirowski, Philip. (1988), Against mechanism. Lanham, Rowman \& Littlefield. . (1991), More heat than light: economics as social physics, physics as nature's economics. Cambridge, Cambridge University Press.

(2013), Never let a serious crisis go to waste: how neoliberalism survived the financial meltdown. Londres, Verso.

MüLLER, Lúcia Helena. (2006), Mercado exemplar: um estudo antropológico sobre a bolsa de valores. Porto Alegre, Zouk. . (2007), “Livre mercado". Civitas, 2 (3): 301-325.

Pardo-Guerra, Juan Pablo. (2015), "Making markets: infrastructures, engineers and the moral technologies of finance". Disponível em https://pardoguerra.files.wordpress. com/2014/11/141124-making-markets2.pdf, acesso em 30/12/2016.

Pardo-Guerra, Juan Pablo \& MacKenzie, Donald. (2014), "The politics of fragmentation: liberalism, market equality, and the technological re-configuration of American finance”. Trabalho apresentado na conferência da Society for the Advancement of Socio-Economics, 10-12 jul., Chicago.

Polanyi, Karl. (1944), The great transformation: the political and economic origins of our time. Boston, Beacon.

RILEs, Annelise. (2011), Collateral knowledge: legal reasoning in the global financial markets. Chicago, University of Chicago Press.

Sassen, Saskia. (2001), The global city: New York, London, Tokyo. Princeton, Princeton University Press.

Simmel, Georg. (2004), The philosophy of money. Londres, Routledge.

STRATHERN, Marilyn. (2005), Kinship, law and the unexpected: relatives are always a surprise. Cambridge, Cambridge University Press.

TAYlor, Charles. (2002), “Modern social imaginaries”. Public Culture, 1 (14): 91-124. 
Weber, Max. (1978), Economy and society: an outline of interpretive sociology. Berkeley, University of California Press.

. (2000), "Stock and commodity exchanges [Die Börse (1894)]". Theory and Society, 2 (29): 305-338.

Zelizer, Viviana A. (2005), “The priceless child revisited”. In: Qvortrup, Jens (org.). Studies in modern childhood: society, agency, culture. Basingstoke, Palgrave Macmillan, pp. 184-200. . (2012), "How I became a relational economic sociologist and what does that mean?".

Politics \& Society, 2 (40): 145-174.

\section{Resumo}

Mercados como espelho

Este artigo interroga a conceitualização convencional dos mercados como redes, instituições e realizações performativas ao apresentá-los como espelhos culturais que refletem as idiossincrasias e modos de organização social de seus ambientes. Estendendo a metáfora weberiana do mercado como comunidades e combinando-a com recentes teorias antropológicas do parentesco, o artigo propõe compreender processos de mercado como espaços de produção de relações sociais em vez de transações meramente impessoais. Utilizando discussões a respeito de compensação e trocas nos mercados financeiros contemporâneos como um exemplo, o artigo defende repensar o papel e a ontologia dos mercados na vida moderna.

Palavras-chave: Mercados; Parentesco; Relações; Finanças; Infraestruturas.

\section{Abstract}

\section{Markets as mirrors}

This paper queries the conventional conceptualization of markets as networks, institutions, and performative realizations by presenting them as cultural mirrors that reflect the quirks and modes of social organization of their environments. Extending the Weberian metaphor of markets as communities, and combining these with recent anthropological theories of kinship, the paper argues for understanding market processes as sites for the production of social relations rather than merely impersonal transactions. Using discussions of settlement and trading in contemporary financial markets as an example, the article advocates rethinking the role and ontology of markets in modern life.

Keywords: Markets; Kinship; Relations; Finance; Infrastructures.

Texto recebido em 3/9/2016 e aprovado em 14/10/2016. DoI:10.11606/0103-2070.ts2017.12 0258 .

JUAN PABLO PARDO-GUERRA é doutor em estudos de ciência e tecnologia pela University of Edinburgh e professor assistente de sociologia na University of California, San Diego. E-mail: jpardoguerra@ucsd.edu. 